\title{
Manifestações culturais da América Latina por uma saúde humanizada: um projeto de extensão no CAPSad de Foz do Iguaçu
}

\author{
Fidel Pascua Vílchez ${ }^{1}$ \\ Camila Cristina Loureiro de Mauro ${ }^{2}$
}

Resumo: relato de experiência do projeto de extensão Manifestações culturais da América latina por uma saúde humanizada, desenvolvido durante o segundo semestre de 2016 e o primeiro de 2017 por docentes e discentes da Universidade Federal da Integração LatinoAmericana (UNILA) em parceria com o Centro de Atenção Psicossocial Álcool e Drogas (CAPSad) de Foz do Iguaçu - PR. Com base nas Portarias SAS/MS n 224/1992, GM/MS n ${ }^{\circ}$ 336/2002, GM/MS n 816/2002, Gondim, Peter et alii e o Relatório Final da IV Conferência Nacional de Saúde Mental, organizamos, sob a supervisão da Direção do Centro, uma série de oficinas destinadas aos frequentadores, com periodicidade quinzenal, sobre temática latinoamericana e relacionadas com a Terpaia Ocupacional (TO). Como resultado da ação, foram produzidas 84 caixas MDF e 42 peças de cerâmica pintadas, cuja elaboração, exposição e/ou posterior presenteado entre familiares, amigos e visitantes do Centro contribuiu para o fortalecimento da sinergia dos usuários, da sua autoestima e abriu o caminho para futuras colaborações entre o Centro e a Universidade. Ao mesmo tempo, fizemos pesquisa sobre a organização e o funcionamento do CAPSad de Foz do Iguaçu, bem como do perfil dos usuários frequentadores. Concluímos que a maioria pertence ao gênero masculino, sua idade oscila entre os 23 e 46 anos, possui uma formação acadêmica que não atinge o ensino fundamental completo, vive em situação de desemprego, sua experência laboral anterior estava relacionada com trabalhos braçais e está em situação econômica desfavorável.

Palavras-chave: Oficina de artesanato; Terapia Ocupacional; Inclusão social.

\section{Cultural expressions of Latin America for an humanised health: a science outreach project at Foz do Iguassu CAPSad}

Abstract: experience report on the science outreach project Cultural expressions of Latin America for an humanised health, developed during 2016's second semester and 2017's first one by Universidade Federal da Integração Latino-Americana (UNILA) teachers and students, in partnership with Centro de Atenção Psicossocial Álcool e Drogas (CAPSad) in Foz do Iguassu - PR. Based on Ordinances SAS/MS n ${ }^{\circ} 224 / 1992$, GM/MS n 336/2002, GM/MS n ${ }^{\circ}$ $816 / 2002$, Gondim, Peter et alii and the IV National Conference on Mental Health final report, we organized, under the Director's supervision, a series of workshops headed to users, with a fortnightly periodicity, on Latin American themes and related to Occupational Therapy (TO). As a result, were produced $84 \mathrm{MDF}$ boxes and 42 painted pieces of pottery, whose elaboration, display and/or gift afterwards to relatives, friends and Center visitors contribuited to enhancement of synergy of users, their self-worth and opend a path for new partnerships between the Center and the University. Besides, we made a research about CAPSad organization and operation in Foz do Iguassu, as well as the haunting users profile. We conclude that most of them belongs to male gender, aged between 23 and 46, degree not

\footnotetext{
${ }^{1}$ Doutor em Estudos da Linguagem. Universidade Federal da Integração Latino-Americana (UNILA). E-mail: fidel.vilchez@unila.edu.br

${ }^{2}$ Discente do curso de Saúde Coletiva. Universidade Federal da Integração Latino-Americana (UNILA). E-mail: camila.mauro@aluno.unila.edu.br
} 
reaching complete primary school, lives in unemployment, previous work experienced in manual labour and living in a bad economic situation.

Keywords: Handicraft workshop. Occupational Therapy. Social inclusion.

\section{INTRODUÇÃO}

O presente artigo é um relato de experiência do projeto de extensão Manifestações culturais da América Latina por uma saúde humanizada, desenvolvido durante o segundo semestre de 2016 e o primeiro de 2017 no Centro de Atenção Psicossocial Álcool e Drogas (CAPSad) de Foz do Iguaçu por discentes bolsistas e voluntários da Universidade Federal da Integração Latino-Americana (UNILA), pertencentes aos cursos de Saúde Coletiva, Antropologia e Desenvolvimento Rural e Segurança Alimentar.

O projeto surgiu como uma proposta interdisciplinar que visava (e visa) a unir conhecimentos teóricos e práticos no levantamento de problemáticas da comunidade desta cidade, localizada na fronteira trinacional; outrossim, um projeto, portanto, com vocação latino-americanista, voltado à promoção da inclusão social e à socialização do conhecimento.

Nesse sentido, o fato de que a UNILA fosse uma universidade nova, atraísse em pouco tempo milhares de novos estudantes, muitos estrangeiros vindos de países da América Latina e oferecesse um projeto político-pedagógico diferente, fez com que, alimentado por uma parte da opinião pública da cidade, os estudantes da instituição fossem vistos por uma parte da sociedade iguaçuense com preconceito e fossem associados também ao consumo de álcool e drogas.

Isso nos fez refletir sobre a necessidade de criar uma ação de extensão que viesse a combater todos esses preconceitos injustificados e oferecesse uma visão positiva dos estudantes, justamente no contexto de marginalização que eles estavam sofrendo.

Desse jeito, Manifestações culturais da América Latina por uma saúde humanizada nasceu com o intuito de ser um elo entre a Universidade e a comunidade iguaçuense e cumprir com a função básica de uma ação de extensão universitária, conforme regulamentado na Resolução COSUEX n ${ }^{\circ}$ 001/2015 da UNILA. De acordo com UNILA, (2015, p.1):

A ação de extensão da UNILA é constituída como processo educativo, cultural, científico e político que, artículada de forma indissociável com o ensino e a pesquisa, visibiliza e media a relação transformadora entre a Universidade e a sociedade.

A iniciativa de criar um projeto que relacionasse o CAPSad com a UNILA partiu dos próprios discentes do curso de Saúde Coletiva, os quais, no momento de abrir o Edital de submissão de propostas de ações de extensão, estavam estudando como surgem novas perspectivas para a atenção e o cuidado em saúde mental, a partir do movimento de reforma psiquiátrica brasileiro, iniciado em meados dos anos 70 por profissionais de saúde mental e Revista Extensão em Foco, no 16, Jul./ Set. (2018), p. X - X. 
familiares de pessoas com transtornos mentais contrários ao modelo manicomial então vigente.

Em 1986 começam a ser construídos então, como uma das estratégias alternativas ao hospital psiquiátrico, Centros de Atenção Psicossocial (CAPS), que recebem sua oficialização a partir da Portaria SAS/MS n 224 de 29 de janeiro de 1992. De acordo com BRASIL, (1992, p. 2):

Os NAPS/CAPS são unidades de saúde locais/regionalizadas que contam com uma população adscrita definida pelo nível local e que oferecem atendimento de cuidados intermediários entre o regime ambulatorial e a internação hospitalar, em um ou dois turnos de 4 horas, por equipe multiprofissional.

Como um dos resultados deste movimento, a Lei da Reforma Psiquiátrica, após doze anos de tramitação, foi promulgada em 6 de abril de 2001 sob o número 10.216. Em que pese que o projeto original tenha sido rejeitado, o que o substituiu foi um passo decisivo para o redirecionamento do modelo assistencial em saúde mental no Brasil, abrindo precedente para a regulamentação e ampliação dos CAPS pela Portaria 336/GM, de 19 de fevereiro de 2002. De acordo com Brasil, (2002, p.1):

As três modalidades de serviços cumprem a mesma função no atendimento público em saúde mental, distinguindo-se pelas características descritas no Artigo $3^{\circ}$ desta Portaria, e deverão estar capacitadas para realizar prioritariamente o atendimento de pacientes com transtornos mentais severos e persistentes em sua área territorial, em regime de tratamento intensivo, semi-intensivo e não intensivo, conforme definido adiante.

Os CAPS constituem assim a principal estratégia do processo de reforma psiquiátrica, como instituições destinadas a acolher os pacientes com transtornos mentais, estimular sua integração social e familiar, apoiá-los em suas iniciativas de busca da autonomia, oferecerlhes atendimento médico e psicológico. Sua característica principal é buscar integrá-los a um ambiente social e cultural concreto, designado como "seu território", o espaço da cidade onde se desenvolve a vida quotidiana de usuários e familiares. Porém, esse processo de reforma ainda está em construção. De acordo com Vargas et alii, (2014, p. 1):

Conforme a dimensão epistemológica do referencial da reforma psiquiátrica, isso nos permite apontar que, apesar dos novos saberes e conhecimentos produzidos com o advento da reforma, por meio da ruptura do olhar psiquiátrico diante da doença mental, ainda há muitos profissionais que ainda estão atrelados a esse olhar; por isso, as instituições de formação de profissionais de nível médio em enfermagem e os próprios enfermeiros devem ficar atentos para a transformação desse olhar, o que requer mudança de concepção do "objeto" da saúde mental e a necessidade de descontruir/reconstruir esse novo jeito de trabalhar nesse novo paradigma psicossocial.

Eles integram o Sistema Único de Saúde (SUS) brasileiro, instituído pelas Leis Federais 8.080/1990 e 8.142/1990 que preveem o acesso universal, público e gratuito aos Revista Extensão em Foco, nº 16, Jul./ Set. (2018), p. X - X. 
serviços de saúde, acompanhando o instituído pela Constituição Federal de 1988 que prevê a saúde como direito social e dever do Estado.

Pessoas em sofrimento psíquico relacionado ao uso abusivo e dependência de álcool ou outras drogas têm direito, desde a instituição do Programa Nacional de Atenção Comunitária Integrada a Usuários de Álcool e outras Drogas pela Portaria nº 816/GM/MS, de 30 de abril de 2002, a ser atendidas por CAPS específicos, os Centros de Atenção Psicossocial para atendimento de pacientes com dependência e/ou uso prejudicial de álcool e outras drogas (CAPSad).

Estes têm como objetivo oferecer atendimento diário a pacientes que fazem um uso prejudicial de álcool e outras drogas, permitindo o planejamento terapêutico dentro de uma perspectiva individualizada de evolução contínua, valendo-se, para tanto, de atendimento individual, atendimentos em grupo, oficinas terapêuticas e visitas domiciliares. De acordo com Brasil, (2002, p. 1):

[...] Instituir, no âmbito do Sistema Único de Saúde, o Programa Nacional de Atenção Comunitária Integrada a Usuários de Álcool e Outras Drogas, a ser desenvolvido de forma articulada pelo Ministério da Saúde e pelas Secretarias de Saúde dos estados, Distrito Federal e municípios, tendo por objetivos:

I - Articular as ações desenvolvidas pelas três esferas de governo destinadas a promover a atenção aos pacientes com dependência e/ou uso prejudicial de álcool ou outras drogas;

II - Organizar e implantar rede estratégica de serviços extra-hospitalares de atenção aos pacientes com esse tipo de transtorno, articulada à rede de atenção psicossocial;

III - Aperfeiçoar as intervenções preventivas como forma de reduzir os danos sociais e à saúde representados pelo uso prejudicial de álcool e outras drogas;

IV - Realizar ações de atenção/assistência aos pacientes e familiares, de forma integral e abrangente, com atendimento individual, em grupo, atividades comunitárias, orientação profissional, suporte medicamentoso, psicoterápico, de orientação e outros;

V - Organizar/regular as demandas e os fluxos assistenciais;

VI - Promover, em articulação com instituições formadoras, a capacitação e supervisão das equipes de atenção básica, serviços e programas de saúde mental locais.

É no âmbito das oficinas terapêuticas que se insere nosso trabalho. O projeto Manifestações culturais da América Latina por uma saúde humanizada foi uma das 78 ações de extensão da Universidade Federal da Integração Latino-Americana (UNILA), renovado pela terceira vez desde que iniciou-se em 2014 e que vem realizando atividades culturais de temática latino-americana junto a grupos de usuários, usuárias e profissionais do CAPSad da cidade de Foz do Iguaçu, com o objetivo de contribuir com o trabalho da equipe pela valorização da autoestima e reabilitação psicossocial desta comunidade específica.

Ao longo deste artigo, apresentaremos e analisaremos as percepções dos atores envolvidos nas atividades e, com base nisto, refletiremos sobre a estratégia destas oficinas terapêuticas no contexto particular deste CAPSad.

Revista Extensão em Foco, nº 16, Jul./ Set. (2018), p. X - X. 


\section{Materiais e métodos}

O projeto foi articulado através dos três eixos que devem estruturar um projeto de extensão: o ensino, a pesquisa e a prática das mesmas além dos muros da Universidade.

Para tanto, O grupo de trabalho, sob supervisão do coordenador, elaborou com periodicidade quinzenal uma série de oficinas multidisciplinares das diversas manifestações culturais da América Latina: poesia, teatro, cinema, música, artesanato etc., atendendo também as sugestões dos próprios usuários do Centro ou da Direção do mesmo, organizadas em torno a um tema específico e conforme a um plano de trabalho prévio. Ao mesmo tempo, era escolhido o item correspondente à pesquisa sobre a estrutura e funcionamento do CAPSad.

No dia marcado, as oficinas eram administradas no CAPSad de Foz do Iguaçu, seguindo, basicamente, o esquema seguinte:

- Apresentação das oficinas da sessão: temática, abrangência, objetivos.

- Execução das oficinas, visando a participação ativa dos usuários, tanto de forma individual quanto coletiva.

- Retorno da experiência: bate-papo com os usuários, favorecendo o diálogo que permitisse determinar a produtividade da experiência.

- Retorno da experiência com o Coordenador do Centro.

De forma paralela, os participantes do projeto mantiveram durante os encontros no CAPSad um contato direto com os funcionários do Centro e com os frequentadores do mesmo, como ação combinada de formação e pesquisa, coletando dados sobre seu funcionamento, experiências, etc., os quais, após a correspondente análise, serviram para a elaboração deste trabalho.

A princípio, no intuito de dar continuidade à dinâmica das duas edições anteriores, a ação visava a organizar oficinas de natureza diversa, como música, cinema, literatura, culinária, rodas de conversa, etc.) de temática latino-americana, no intuito de aproximar os usuários da cultura da região, para além dos benefícios terapêuticos que estas oficinas poderiam proporcionar.

As atividades consistiam em exercícios de interação sociocultural entre os envolvidos no projeto. Os objetivos esperados com as atividades eram tanto o de conhecer o sujeito, suas relações sociais e culturais, quanto o de promover a saúde entre os participantes, ou seja, os Revista Extensão em Foco, no 16, Jul./ Set. (2018), p. X - X. 
exercícios nos permitiram conhecer os interesses, necessidades, capacidades e potencialidades dos indivíduos, bem como incentivar comportamentos e atitudes sempre em uma esfera saudável.

Para tanto, fez-se necessário a integração inicial entre os abrangidos no projeto através de dinâmicas de aproximação e reconhecimento para, posteriormente, identificar afinidades e desenvolver atividades relacionadas com expressões culturais latino-americanas sugeridas pelos usuários do Centro e seus profissionais. A seguir, apresentava-se um cronograma de atividades elaborado mais como um plano de trabalho, cabíveis a modificações conforme o interesse dos envolvidos, bem como orientações dos profissionais do Centro (Tabela 1).

Tabela 1: Cronograma de atividades previstas - Agosto 2016.

\section{Atividade I: Expressa-se! (Reconhecimento)}

Data: 03/08/2016

Recursos necessários: Papel A4, canetas, canetinhas, pincéis, tintas.

Descrição da metodologia: Inicialmente, os membros do projeto realizarão suas apresentações pessoais descrevendo a ideia e a condução do projeto, assim como relatando suas experiências no âmbito latino-americanista. Logo após, cada usuário do CAPS AD, como maneira de se apresentar, irá se manifestar livremente numa folha A4 através de desenhos, trechos de músicas, poemas, frases, reflexões ou deixar a folha em branco caso optar somente pela apresentação oral e/ou através de expressões corporais, sendo desse modo a manifestação livre e opcional.

Objetivo da dinâmica: A arte é o lado sensível do ser humano e através dessas simples manifestações artísticas há a identificação entre os sujeitos, seja por meio de gostos musicais, literários ou mesmo seja pelas expressões emocionais apresentadas ao grupo.

Atividade II: Declamações de letras musicais

Data: $17 / 08 / 2016$

Recursos necessários: Aparelho de som, letras de músicas impressas.

Descrição da metodologia: No encontro anterior, os organizadores das atividades através da aproximação com os usuários e profissionais do Caps Ad irão tentar identificar as preferências musicais dos participantes. Assim para essa atividade, os organizadores trarão impresso diversas letras de músicas buscando atender aos interesses de todos e a composição será trabalha e debatida por meio de teatralização, declamação, forma cantata dentre outros (livre). Espera-se que haja troca de músicas entre os envolvidos, de maneira que um integrante apresente a música escolhida pelo outro. A cada usuário sera entregue uma folha de papel, na qual de forma livre possa se expressar sobre suas sensações a respeito da música.

Objetivo da dinâmica: As letras e seus estilos musicais traduzem muito sobre a realidade e expressões do sujeito. Ao manifestar artisticamente o gosto musical alheio, almeja-se uma empatia entre os participantes. 
Atividade III: Ai, que saudade!

Data: 31/08/2016

Recursos necessários: Dependerá dos jogos propostas.

Descrição da metodologia: Em um contexto nostálgico, sera proposto a cada usuário a confecção de jogos (propostos pelos mesmos na semana anterior), para que a atividade além de trabalhar com a capacidade criativa, possa também servir de instrumentos para as oficinas futuras, bem como de atividade recreativa para os mesmos. $\mathrm{Na}$ atividade, os orientadores da mesma, trarão para o coletivo o conhecimento bem como a possibilidade de confecção de jogos utilizados em distintas partes da Latino-America.

Objetivo da dinâmica: Nostalgia será o sentimento que norteará a atividade, através de recordações dos jogos e brincadeiras preferidas enquanto crianças os usuários do Caps Ad se divertirão e ao mesmo tempo realizarão significantes atividades recreativas.

Fonte: Dados dos pesquisadores (2016-17)

No entanto, por sugestão da coordenação do CAPSad, após algumas experiências nas edições anteriores, fomos orientados a focar somente em atividades artesanais, pois, segundo alegaram: "Em outros tipos de oficinas não-manuais, os usuários tendiam facilmente à dispersão, dadas os seus históricos de dependência".

Além disso, outrora os frequentadores já haviam se beneficiado com oficinas de artesanato, por meio de contrato firmado pela gestão municipal, que por motivos alheios ao nosso conhecimento não foi renovado, de forma que esta atividade em particular acabou por se apresentar como uma demanda oportuna.

Desse jeito, atendendo as recomendações da Direção do Centro, foram organizadas uma série de oficinas de artesanato destinadas aos usuários do CAPSad, sob a monitoração da mesma.

Estas oficinas de artesanato complementaram as atividades terapéuticas desenvolvidas pela equipe multiprofissional em saúde, relacionadas com a Terapia Ocupacional (TO), orientadas para a emancipação e autonomia de pessoas que, por causa da sua problemática específica (uso continuado de substâncias alteradoras da conduta) apresentam dificuldade na inserção e participação na vida social. De acordo com Brasil, (2007, p. 1):

[...] voltada aos estudos, à prevenção e ao tratamento de indivíduos portadores de alterações cognitivas, afetivas, perceptivas e psico-motoras, decorrentes ou não de distúrbios genéticos, traumáticos e/ou de doenças adquiridas, através da sistematização e utilização da atividade humana como base de desenvolvimento de projetos terapêuticos específicos, na atenção básica, média complexidade e alta complexidade.

A Terapia Ocupacional visa a desenvolver as capacidades que permitam o indivíduo envolver-se em atividades que ajudem a aumentar sua autoestima e valorização, facilitando, desse jeito, sua inclusão na sociedade, independente da sua condição de saúde, social, seu estilo de vida ou contexto. De acordo com Brasil, (2007, p. 1): 
O Terapeuta Ocupacional compreende a Atividade Humana como um processo criativo, criador, lúdico, expressivo, evolutivo, produtivo e de auto manutenção e o homem, como um ser práxico interferindo no cotidiano do usuário comprometido em suas funções práxicas objetivando alcançar uma melhor qualidade de vida.

As oficinas ocorreram quinzenalmente, sempre às quartas-feiras, após o café da manhã coletivo, no horário das dez horas da manhã, na terceira sala de oficinas do estabelecimento. Sua duração variava de uma hora a uma hora e vinte minutos.

As atividades envolveram técnicas de pintura em madeira e cerâmica, como pátina, craquelê, colagem (decoupage) e pintura livre, produção de artigos de decoração tais como velas, ímãs de geladeira, porta-retratos e outros.

Os materiais utilizados advieram tanto dos recursos financeiros que a universidade disponibilizou desde a primeira edição do projeto, quanto do próprio depósito de materiais do departamento de Terapia Ocupacional do centro, e também do acúmulo de material reciclável proveniente de nosso uso pessoal.

A verba disponibilizada pela Pró-Reitoria de Extensão da Universidade, através de Edital PROEX, foi o que possibilitou a compra dos materiais necessários para o desenvolvimento das oficinas, por valor de três mil reais. Foram os seguintes:

84 caixas MDF (14x6 modelos), 42 peças de cerâmica (14x3 modelos), 24 godê, 12 tanquinhos, 50 potes de tinta em diferentes cores, 4 potes de cola de $1 \mathrm{~kg}, 20$ rolinhos de espuma, 20 potes de verniz acrílico de $250 \mathrm{ml}, 3$ folhas texturadas, 5 lixas de $150 \mathrm{~mm}, 1$ trincha, 36 bandejas de isopor, 2 pacotes de guardanapos, 14 kits craquelê, 14 pinceis pátina, 14 recortes, 14 bases acrílicas de 250ml, 35 lixas de 280mm, 1 pote de verniz geral, 6 potes de solvente, 14 folhas decoupage e um soprador.

Além dos materiais específicos, contamos com a colaboração técnica do pessoal da empresa fornecedora durante as duas primeiras oficinas, que orientou as bolsistas e os participantes quanto às técnicas de preparação, montagem, pintura e acabamento das peças MDF e de cerâmica.

Durante a semana, a equipe de bolsistas pesquisava sobre atividades que poderiam ser realizadas e quais as mais adequadas tendo em conta o tempo disponível, número de participantes e benefícios aos mesmos. Isso feito, passava-se à coleta do material, e, no caso de escolhermos uma atividade que não era de nosso saber prévio, estipulávamos um dia na semana para aprender e testar a técnica. Em geral aprendemos com pessoas de nosso convívio ou orientações disponíveis em websites e vídeos na internet. No dia estipulado procurávamos chegar com alguns minutos de antecedência para preparar a sala.

Revista Extensão em Foco, nº 16, Jul./ Set. (2018), p. X - X. 
Nas primeiras oficinas, nos apresentávamos e apresentávamos o que iríamos fazer. Todos os participantes eram incentivados a construírem a oficina, desde a confecção do artefato a ser desenvolvido à limpeza e organização dos materiais utilizados e local ocupado. Procurávamos deixar todos à vontade para entrar ou sair sem ter que pedir autorização, para conversar, sem qualquer tipo de censura para temas, desde que fosse mantido o devido respeito, e brincadeiras ou piadas saudáveis que não se baseassem em nenhum tipo de opressão eram muito bem-vindas.

A ideia era manter uma relação de horizontalidade em que nós não fossemos vistas como superiores ou dotadas de qualquer autoridade.

Após um tempo, não era mais necessário repetir estas orientações, pois a maioria dos participantes já conhecia bem o funcionamento das oficinas e quanto às orientações nunca tivemos maiores problemas, exceto por algum tipo de piada machista, perante à qual atuamos no sentido de debater de maneira pedagógica a questão do machismo na sociedade, sem perder o foco da atividade em andamento.

Nas atividades de pintura, a técnica era sempre uma sugestão, de forma que o participante gozava de total liberdade para fazer de forma diferente se assim o desejasse, valorizando assim a forma de expressão própria de cada um.

A decisão sobre o futuro do produto concebido também era de cada um, existindo a opção de deixarem para o bazar do centro caso desejassem; no entanto, sempre os encorajávamos a presentear pessoas queridas, pela importância que tem o fortalecimento da rede de afetos do indivíduo na reabilitação psicossocial.

Durante e após as oficinas, quando havia tempo, discutíamos sobre a repercussão da realização destas atividades na vida individual e coletiva de cada um.

\section{Resultados e discussão}

Como resultado da ação, foram produzidas 84 caixas MDF e 42 peças de cerâmica pintadas, cuja elaboração, exposição e posterior venda informal a familiares, amigos e visitantes do Centro contribuiu para o fortalecimento da sinergia entre os usuários, a adquisição de novas habilidades e despertou o interesse em participar da próxima edição do projeto, a partir de 2018, continuando a parceria entre o Centro e a Universidade.

A distribuição das oficinas, objetos produzidos e usuários participantes foi a seguinte (Tabela 2):

Tabela 2: Distribuição de oficinas, objetos produzidos e usuários participantes

\begin{tabular}{|c|c|c|c|}
\hline Oficina & Data & Participantes & Objeto \\
\hline
\end{tabular}

Revista Extensão em Foco, no 16, Jul./ Set. (2018), p. X - X. 


\begin{tabular}{|c|c|c|c|}
\hline $\mathrm{I}$ & $03 / 08 / 2016$ & 10 & \multirow{2}{*}{ Caixa de chá $24 \times 15,5 \times 07$} \\
\hline II & $17 / 08 / 2016$ & 10 & \\
\hline III & $31 / 08 / 2016$ & 9 & \multirow{2}{*}{ Caixa de chá 16x08x07 } \\
\hline IV & $14 / 09 / 2016$ & 10 & \\
\hline $\mathrm{V}$ & $28 / 09 / 2016$ & 10 & \multirow{2}{*}{ Caixa tampa de sapato $20 \times 20 \times 08$} \\
\hline VI & $19 / 10 / 2016$ & 10 & \\
\hline VII & $09 / 11 / 2016$ & 8 & \multirow{2}{*}{ Caixa de chá 16x16x07 } \\
\hline VIII & $23 / 11 / 2016$ & 10 & \\
\hline IX & $01 / 12 / 2016$ & 9 & \multirow{2}{*}{ Caixa tampa de sapato $17 \times 17 \times 06$} \\
\hline $\mathrm{X}$ & $15 / 12 / 2016$ & 10 & \\
\hline XI & $08 / 03 / 2017$ & 10 & \multirow{2}{*}{ Caixa tampa de sapato $20 \times 15 \times 10$} \\
\hline XII & $22 / 03 / 2017$ & 10 & \\
\hline XIII & $05 / 04 / 2017$ & 10 & \multirow{2}{*}{ Bojudinho de cerâmica $4 \times 5$} \\
\hline XIV & $19 / 04 / 2017$ & 10 & \\
\hline $\mathrm{XV}$ & $03 / 05 / 2017$ & 10 & \multirow{2}{*}{ Bojudinho de cerâmica $5 \times 7$} \\
\hline XVI & $17 / 05 / 2017$ & 10 & \\
\hline XVII & $31 / 05 / 2017$ & 10 & \multirow{2}{*}{ Bojudinho de cerâmica $7 x 7$} \\
\hline XVIII & 07/06/2017 & 10 & \\
\hline XIX & $21 / 06 / 2017$ & 10 & Confraternização e despedida \\
\hline
\end{tabular}

Fonte: Dados dos pesquisadores (2016-2017).

A pesquisa realizada permitiu obter os dados necessários que nos permitiram entender a dinâmica do Centro, em função da normativa vigente e da sua estrutura organizativa, bem como estabelecer padrôes quanto as caraterísitcas dos usuários que o frequentam.

a) CAPSad Solidariedade:

A portaria $n^{\circ} 816 / \mathrm{GM} / \mathrm{MS}$, de 30 de abril de 2002 estabelece que nos três anos seguintes de sua promulgação fossem instituídos 250 CAPSad, sendo 120 deles em capitais e municípios com população igual ou superior a 200.000 habitantes. De acordo com Brasil, (2002, p. 1):

[...] Estabelecer que, em virtude dos diferentes níveis de organização das redes assistenciais existentes nos estados e no Distrito Federal, da diversidade das características populacionais existentes no País e da variação da incidência dos transtornos causados pelo uso abusivo ou dependência de álcool e outras drogas, deverão ser implantados no País, nos próximos três anos, 250 Centros de Atenção Psicossocial para Atendimento de Pacientes com dependência e/ou uso prejudicial de álcool e outras Drogas, em Etapas Anuais de Implantação, conforme segue:

Revista Extensão em Foco, nº 16, Jul./ Set. (2018), p. X - X. 
a - Etapa 1 - Ano de 2002/2003 - 120 (cento e vinte) Centros distribuídos estrategicamente nas capitais e municípios com população igual ou superior a 200.000 habitantes - conforme planilha constante do Anexo II desta Portaria;

b - Etapa 2 - Ano de 2004 - 130 (cento e trinta) Centros de Atenção Psicossocial para Atendimento de Pacientes com Transtornos causados pelo uso prejudicial e/ou dependência de álcool e outras drogas, sendo 80 (oitenta) distribuídos estrategicamente, na proporção de 01 CAPS para cada 500.000 habitantes, em grandes regiões metropolitanas, que já terão implantado a parte inicial da rede necessária (etapas $1 \mathrm{e}$ 2), além de mais 50 (cinquienta) a serem localizados em cidades com menos de 200.000 habitantes de acordo com necessidades estratégicas/epidemiológicas.

Foz do Iguaçu, cidade que conta hoje com uma população de cerca de 263 mil habitantes, no entanto, implementou o CAPS-ad denominado "Solidariedade" somente em fevereiro de 2006. Este localiza-se no distrito sanitário oeste da cidade, em um bairro próximo ao centro da cidade, porém de difícil acesso, chamado Vila Yolanda.

Segundo Gondim, Peiter et alii (2008) “O distrito sanitário é a unidade organizacional mínima do SUS, de acordo com seu princípio de territorialização, que pressupõe a descentralização das ações e serviços de saúde com a finalidade de horizontalizá-las" (p. 28).

Este centro contava, no ano de 2016, com onze profissionais no total, sendo um clínico geral, um enfermeiro, um assistente social, três psicólogos, uma estagiária contratada, duas recepcionistas, um auxiliar administrativo e uma auxiliar de serviços gerais.

Sua estrutura física conta com: seis banheiros, sendo que dois localizam-se no hall, um na sala da enfermagem, um no consultório médico, um masculino e um feminino para funcionários, e outro na área externa que, no entanto, não encontra-se em condições de uso; um consultório médico; uma sala de enfermagem; uma sala de acolhimento para usuários e familiares; uma sala de equipe; três salas para oficinas terapêuticas; uma recepção; dois depósitos de materiais e lavanderia; um depósito; uma biblioteca uma sala extra sem uso; uma sala de materiais de Terapia Ocupacional; uma sala de administração; uma cozinha; uma copa; um hall e uma quadra comunitária.

O CAPSad Solidariedade entra funciona de segunda-feira a sexta-feira a partir das sete da manhã até às cinco da tarde, porém o horário de atendimento se dá das oito às onze e meia da manhã. Neste período os usuários são atendidos, preparam e tomam café da manhã, realizam atividades recreativas e participam de diferentes tipos de oficinas, como Narcóticos Anônimos, Alcoólicos Anônimos e oficinas terapêuticas, figurando entre elas esta ação de extensão. Ao final do período os usuários são responsáveis pela limpeza dos locais de uso comum, como banheiro e cozinha.

Para o início das atividades, em maio de 2016, a equipe nos recebeu para nos conhecer, dado que nas edições anteriores desta ação outros estudantes eram responsáveis Revista Extensão em Foco, nº 16, Jul./ Set. (2018), p. X - X. 
pelas oficinas. Fomos informadas sobre os diferentes aspectos de funcionamento da unidade $\mathrm{e}$ diretrizes de conduta. Quanto à vestimenta, deveríamos dar preferência a roupas sem decotes e não muito justas, pois, segundo a equipe: "por sermos mulheres alguns usuários tem tendências afloradas e olham mesmo", motivo pelo qual as enfermeiras preferem usar jaleco, o que também nos foi sugerido.

Recomendaram-nos também que não revelássemos informações pessoais como endereço, telefone ou e-mail, pois: "muitos tendem a querer fazer parte da sua vida", e que buscássemos não tocar no assunto de álcool e drogas a todo momento, porém se o assunto partisse deles, não haveria problema em ouvir e conversar sobre, tendo o bom senso como guia nestes casos.

Por fim, nos foi requisitado manter sigilo total quanto às identidades dos usuários, uma vez que o centro atende pessoas de diversas áreas da cidade que poderiam ser as mesmas de nosso convívio.

Cabe salientar que nos foi solicitado pela equipe que déssemos preferência a atividades de artesanato, pois, por se tratar de um trabalho manual, desenvolveria melhor a concentração dos usuários que, por seus históricos e pela utilização de medicamentos controlados, a têm prejudicada, além de já estarem adaptados a este tipo de atividade uma vez que já vinha sendo realizada na edição anterior.

b) O usuário:

Utilizaremos neste trabalho a denominação "usuário" para referirmo-nos aos frequentadores do CAPSad, por entendermos que a denominação "paciente" não condiz com a ideia de um sujeito ativo em seus processos de saúde; pelo contrário, retira-lhe esta parcela de responsabilidade, dando a ideia de passividade perante ao que lhe é atribuído pela equipe de saúde.

Usuário, assim, não se refere ao termo comum "usuário de álcool ou drogas", e sim um indivíduo que utiliza o serviço de saúde e tem participação ativa e poder de decisão sobre sua saúde e seu tratamento, na linha do que sugere o Relatório Final da IV Conferência Nacional de Saúde Mental Intersetorial de 2010. De acordo com Brasil, (2010, p. 63):

[...] É necessário adotar um modelo de saúde humanizado que considere o cuidado integral e a ativa participação de todos, principalmente a dos próprios usuários, na elaboração e condução dos seus projetos terapêuticos, fortalecendo o "protagonismo social", no sentido de desenvolver autonomia e autodeterminação.

Segundo informações da coordenação do próprio centro, em média são atendidas de 90 a 110 pessoas por semana, divididas de forma mais ou menos equânime ao longo dos dias 
da semana. A idade varia entre 23 e 46 anos de idade, sendo que homens respondem por 90\% da população de frequentadores. Em sua maioria, tanto mulheres quanto homens frequentadores estão desempregados, porém em suas profissões anteriores eram trabalhadores braçais, como pedreiros e empregadas domésticas. Entre 60 e $70 \%$ têm apenas o ensino fundamental incompleto e a situação econômica da maioria é desfavorável.

Quanto à dependência, 60\% são alcoolistas enquanto os outros $40 \%$ referem-se ao abuso de outras drogas, como crack e cocaína. Não é possível traçar a quantidade de usuários que dependem de medicamentos, pois trata-se de uma dependência oculta que muitas vezes se confunde com o próprio tratamento, mas estima-se que a proporção de usuários que estão sob efeito de medicamentos psiquiátricos há muito mais tempo do que o recomendado seja de dois a cada dez.

A itinerância da população frequentadora do centro é grande, porém a equipe informou lidar com isso sem maiores problemas, uma vez que, por se tratar de um centro de caráter aberto, se trata de algo já previsto.

Para participar das oficinas terapêuticas, eram selecionados por um membro da equipe, em geral uma psicóloga, entre 8 e 10 participantes, e a princípio também acompanharam alguns estagiários.

O critério de seleção baseava-se no grau de estabilidade do usuário e no tipo de atividade que seria desempenhada, porém com o cuidado de não serem sempre os mesmos, para que houvessem mais oportunidades de participação. Também em relação ao gênero as oficinas sempre foram mistas, porém não exatamente equilibradas, contando com uma proporção de aproximadamente 7 homens e 3 mulheres, pois, como dito, a maioria dos usuários do centro é do gênero masculino. No total, participaram das oficinas 34 frequentadores do centro diferentes

\section{Conclusões}

A participação no projeto Manifestações Culturais da América Latina por uma saúde Humanizada resultou em uma grande experiência de aprendizado junto com os funcionários do CAPSad de Foz do Iguaçu e veio a acrescentar a formação adquirida nas aulas do curso de Saúde Coletiva durante os semestres letivos de 2016 e 2017.

Além disso, contribuimos com a função extensionista da Universidade, levando a insituição além dos seus muros, desenvolvendo atividades de ensino, pesquisa e extensão.

Em relação ao ensino, divulgamos entre os frequentadores do CAPSad Solidaridade a variedade e riqueza da cultura latino-americana em múltiplas disciplinas: literatura, cinema, 
teatro, música, culinária; também diferentes habilidades em diversas disciplinas artísticas, como: artesanato, macramê, decoupage, decoração, pintura etc.

Quanto à pesquisa, primeiramente aumentamos o nosso conhecimento acerca do funcionamento SUS, dos CAPS em geral e do CAPSad em particular.

O convívio com o pessoal do Centro durante os encontros ajudou a compreendermos a dinâmica de trabalho com usuários de substâncias alteradoras da conduta, suas caraterísticas específicas, diferentes terapias voltadas à reparação de danos, a recuperação da autoestima do indivíduo e a sua reinserção social.

A análise da realidade dos frequentadores do Centro mostrou que a maioria pertence ao gênero masculino, sua idade oscila entre os 23 e 46 anos, possuem uma formação acadêmica que não atinge o ensino fundamental completo, vive em situação de desemprego, sua experência laboral anterior estava relacionada com trabalhos braçais e está em situação econômica desfavorável.

Conferimos que, em virtude dessa realidade, junto ao fato de serem usuários de substâncias alteradoras da conduta, muitos frequentadores do CAPSad sofrem no seu cotidiano a estigmatização e a marginalização de uma parte da sociedade iguaçuense, ficando, desse jeito, muito fragilizados.

As atividades desenvolvidas no marco do projeto de extensão Manifestações Culturais da América Latina por uma Saúde Humanizada focavam justamente desenvolver habilidades nos frequentadores que contribuissem a aumentar sua valorização como seres humanos e sua autoestima, complementando as terapias programadas pela Direção do Centro, mais voltadas à reparação de danos físicos e psíquicos dos mesmos.

Aprendemos muito durante a aplicação das oficinas e em contato com o pessoal do CAPSad, mas houve também situações que chamaram a nossa atenção e que despertaram uma atitude crítica quanto ao funcionamento do Centro em relação ao trato com os usuários. Percebemos uma estrita hierarquização na relação entre funcionários e usuários, um viés proibicionista que de certa forma norteava o pensamento dos profissionais, vertical demais ao nosso parecer, seja dito com total respeito, bem como uma certa negação das capacidades individuais e coletivas para com os usuários do sistema.

A modo de exemplo, ficamos surpresos quando, no meio das oficinas, os usuários precisavam pedir autorização para ir no banheiro, o que era entendido por nós como uma total negação da capacidade autônoma do indivíduo.

Revista Extensão em Foco, nº 16, Jul./ Set. (2018), p. X - X. 
As atividades do projeto tiveram eco na imprensa local, o que contribuiu para a visibilização do mesmo, da Universidade e dos benefícios que a nossa instituição proporciona desde faz 7 anos à sociedade iguaçuense, não somente econômicos em relação a alugueis, venda de imóveis, consumo diário nos mercados e lojas da cidade por parte dos discentes, docentes e técnicos da instituição, mas também mediante projetos como este que estamos desenvolvendo.

Finalmente, a participação dos bolsistas e dos colaboradores discentes que fizeram parte da equipe organizadora do projeto contou como como atividade complementar com valor em créditos hora/aula convalidados no currículo do curso, fazendo possível a articulação entre ensino, pesquisa e extensão, como processo educativo operacionalizado através do projeto.

\section{Agradecimentos e apoios}

Agradecemos ao Programa de Bolsas de Extensão da UNILA - PROBEX, pela bolsa disponiblizada.

\section{Referências Bibliográficas}

BRASIL. Ministério da Saúde. Secretaria de Atenção à Saúde. Departamento de Ações Programáticas Estratégicas. Saúde Mental no SUS: os Centros de Atenção Psicossocial. Brasília, Ministério da Saúde, 2004.

BRASIL. Portaria GM/MS n`336/2002. Disponível em: $<$ http://bvsms.saude.gov.br/bvs/saudelegis/gm/2002/prt0336_19_02_2002.html > . Acesso em: 18 de agosto de 2017.

BRASIL. Portaria GM/MS n ${ }^{\circ}$ 816/2002. Disponível em: <http://bvsms.saude.gov.br/bvs/saudelegis/gm/2002/prt0816_30_04_2002.html >. Acesso em: 18 de agosto de 2017.

BRASIL. Portaria SAS/MS n ${ }^{\circ}$ 224/1992. Disponível em: <http://www.saude.mg.gov.br/images/documentos/Portaria_224.pdf $>$. Acesso em: $18 \mathrm{de}$ agosto de 2017.

BRASIL. Sistema Único de Saúde. Conselho Nacional de Saúde. Comissão Organizadora da IV Conferência Nacional de Saúde Mental - Intersetorial. Relatório Final da IV Conferência Nacional de Saúde Mental - Intersetorial, 27 de junho a 1 de julho de 2010. Brasília: Conselho Nacional de Saúde/Ministério da Saúde, 2010.

BRASIL. Conselho Federal de Fisioterapia e Terapia Ocupacional. Definição de Terapia Ocupacional. 2017. Disponível em: <https://www.coffito.gov.br/nsite/?page id=3382>. Acesso em: 18 de agosto de 2017.

GONDIM, Grácia Maria de Miranda; PEITER, Paulo; BARCELLOS, Christovam.; IÑIGUEZ, Luisa; MONKEN, Mauricio.; NAVARRO, Marli.; GRACIE, Renata. O território Revista Extensão em Foco, nº 16, Jul./ Set. (2018), p. X - X. 
da saúde: a organização do sistema de saúde e a territorialização. In: MIRANDA, A. C. D.; BARCELLOS, C.; MOREIRA, J. C.; MONKEN, M. (Org.). Território, ambiente e saúde. Rio de Janeiro, Editora Fiocruz, 2008. p.1-22. Disponível em: <http://www.escoladesaude.pr.gov.br/arquivos/File/TEXTOS CURSO_VIGILANCIA/20.pdf>. Acesso em: 12 de maio de 2017.

UNIVERSIDADE FEDERAL DA INTEGRAÇÃO LATINO-AMERICANA. Resolução COSUEX n ${ }^{\circ}$ 001/2015, que estabelece o Regulamento da Extensão Universitária da UNILA. Em: Boletim de Serviço da UNILA n ${ }^{\circ}$ 141, de 27 de fevereiro de 2015, p. 2-7. Disponível em: 〈https://www.unila.edu.br/sites/default/files/boletim_141_27022015.pdf>. Acesso em: 21 de novembro de 2017.

VARGAS, Divane De; BITTENCOURT, Marina Nelli; ROCHA, SILVA, Anna Carolina Oliveira. Centros de atenção psicossocial álcool/drogas. Inserção e práticas dos profissionais de enfermagem. Em: Escola Anna Nery, Vol. 18, n 1. Rio de Janeiro, 2014. Disponível em: < http://www.scielo.br/scielo.php?script=sci_arttext\&pid=S1414-

$\underline{81452014000100101 \& \operatorname{lng}=e n \& n r m=i s o \& t \operatorname{lng}=p t>}$. Acesso em 21 de novembro de 2017. 